\title{
Optimizing Clinical Decision Support in the Electronic Health Record
}

\section{Clinical Characteristics Associated with the Use of a Decision Tool for Disposition of ED Patients with Pulmonary Embolism}

Dustin W. Ballard ${ }^{1,2}$; Ridhima Vemula²; Uli K. Chettipally ${ }^{3}$; Mamata V. Kene'; Dustin G. Mark ${ }^{5}$; Andrew K. Elms ${ }^{6}$; James S. Lin; Mary E. Reed²; Jie Huang2; Adina S. Rauchwerger2; David R. Vinson 2,8; for the KP CREST Network Investigators

${ }^{1}$ Kaiser Permanente San Rafael Medical Center, San Rafael, CA;

2 Kaiser Permanente Division of Research, Oakland, CA;

${ }^{3}$ Kaiser Permanente South San Francisco Medical Center, South San Francisco, CA;

${ }^{4}$ Kaiser Permanente San Leandro Medical Center, San Leandro, CA

${ }^{5}$ Kaiser Permanente Oakland Medical Center, Oakland, CA;

${ }^{6}$ Kaiser Permanente South Sacramento Medical Center, Sacramento, CA;

${ }^{7}$ Kaiser Permanente Santa Clara Medical Center, Santa Clara, CA;

${ }^{8}$ Kaiser Permanente Roseville Medical Center, Roseville, CA

\section{Keywords}

Decision-support, computerized, pulmonary embolism, electronic health record, research network

\section{Summary}

Objective: Adoption of clinical decision support (CDS) tools by clinicians is often limited by workflow barriers. We sought to assess characteristics associated with clinician use of an electronic health record-embedded clinical decision support system (CDSS).

Methods: In a prospective study on emergency department (ED) activation of a CDSS tool across 14 hospitals between 9/1/14 to 4/30/15, the CDSS was deployed at 10 active sites with an on-site champion, education sessions, iterative feedback, and up to 3 gift cards/clinician as an incentive. The tool was also deployed at 4 passive sites that received only an introductory educational session. Activation of the CDSS - which calculated the Pulmonary Embolism Severity Index (PESI) score and provided guidance - and associated clinical data were collected prospectively. We used multivariable logistic regression with random effects at provider/facility levels to assess the association between activation of the CDSS tool and characteristics at: 1) patient level (PESI score), 2) provider level (demographics and clinical load at time of activation opportunity), and 3) facility level (active vs. passive site, facility ED volume, and ED acuity at time of activation opportunity). Results: Out of 662 eligible patient encounters, the CDSS was activated in $55 \%$ : active sites: $68 \%$ (346/512); passive sites 13\% (20/150). In bivariate analysis, active sites had an increase in activation rates based on the number of prior gift cards the physician had received $(96 \%$ if 3 prior cards versus $60 \%$ if $0, p<0.0001$ ). At passive sites, physicians $<$ age 40 had higher rates of activation $(p=0.03$ ). In multivariable analysis, active site status, low $E D$ volume at the time of diagnosis and PESI scores I or II (compared to III or higher) were associated with higher likelihood of CDSS activation.

Conclusions: Performing on-site tool promotion significantly increased odds of CDSS activation. Optimizing CDSS adoption requires active education. 


\section{Correspondence to:}

Dustin W. Ballard

1600 Los Gamos Drive, Suite 220

San Rafael, CA 94903

Email: dballard30@gmail.com
Appl Clin Inform 2016; 7: 883-898

http://dx.doi.org/10.4338/ACI-2016-05-RA-0073

received: June 1, 2016

accepted: August 17, 2016

published: September 21, 2016

Citation: Ballard DW, Vemula R, Chettipally UK, Kene MV, Mark DG, Elms AK, Lin JS, Reed ME, Huang J,

Rauchwerger AS, Vinson DR, for the KP CREST Network Investigators. Optimizing clinical decision support in the electronic health record - clinical characteristics associated with the use of a decision tool for disposition of ED patients with pulmonary embolism. Appl

Clin Inform 2016; 7: 883-898

http://dx.doi.org/10.4338/ACI-2016-05-RA-0073

Funding:

This study was supported by a grant from The Permanente Federation's Sidney R. Garfield Memorial Fund, Oakland, California 


\section{Background and Significance}

The goal of knowledge translation (KT) is to close the gap between proven science and real-time care delivery. Historically, the adoption of new evidence into clinical practice has lagged a decade or more - with variable uptake across physicians and settings [1,2]. While $\mathrm{KT}$, and implementation science more generally, are relatively new fields of emphasis and study, previous work has identified barriers to effective KT as well as best practices for implementation [3].

For example, Davidoff has stressed the importance of concentrating not only on the diffusion of new validated techniques and treatments into practice but also on the "undiffusion" of previous practice - especially amongst those physicians who may be prone to suffering from inertia when it comes to changing their practice [4]. Michie has described a behavior change wheel framework for identifying well-suited interventions (e.g., education, environmental context, etc.) to combat barriers to implementation of knowledge translation tools [5]. Diner has described four key components to promote knowledge translation: acceptance, application, ability, and recall [6]. Recently, Carpenter and Milne further elucidated five "leaks" of effective KT at the provider level as well as two at the patient/family level (agreement and adherence) [6, 7].

Effective KT can be even more challenging in an unpredictable and fast-moving environment such as the Emergency Department (ED). Here, the pace of care delivery and other workflow barriers can slow the diffusion of new knowledge into practice - especially if implemented in an ad hoc fashion.

To combat these challenges, an emergency medicine (EM) consensus conference recommended the following: building collaborative networks of knowledge translation and emergency medicine researchers, undertaking a multidisciplinary research imperative, defining what knowledge is ready for translation, and building conceptual and theoretical frameworks for knowledge translation research and projects [8].

Others have suggested that knowledge translation may be best accomplished by integrating clinical decision support (CDS) into the clinician-based computerized workflow and by providing recommendations rather than assessments $[9,10]$. However, prior attempts at integrating CDS into the electronic health record (EHR) have been met with variable results, including inconsistent degrees of physician receptiveness and uptake [11-13]. This study was motivated by the goal of evaluating specific predictors of emergency physician uptake of an EHR-based CDS system (CDSS).

\section{Objectives}

We set out to assess the effectiveness of clinician adoption of a CDSS for site-of-care decision making for ED patients with acute pulmonary embolism (PE) and to identify characteristics associated with increased likelihood of tool use. We hypothesized that CDSS activation would be significantly higher at active implementation sites (those with an on-site clinical champion and a structured incentives program) compared with passive sites (those with neither champion nor incentives), and that activation rates would be adversely affected by higher clinical loads - both on the individual provider and facility level.

\section{Methods}

\subsection{Setting}

Kaiser Permanente Northern California (KPNC) is a large integrated health care delivery system that provides comprehensive medical care for more than 3.9 million members at medical centers across the region. Medical center EDs are staffed by more than 500 salaried (board-certified or eligible) emergency physicians and have an annual ED visit census of approximately one million visits a year. Most EDs in our system employ an automated approach to assignment of patients to ED providers [14]. KPNC is supported by a comprehensive inpatient EHR (Epic, Verona, WI) fully deployed in 2010. This investigation utilized CDS provided by an external Web Service-based clinical 
decision support service and accessible via an ED Navigator button within each patient's record. Our setting has been well described previously [15-18].

\subsection{Interventions}

We prospectively studied rates and characteristics of appropriate ED activation of our CDSS across 14 EDs within KPNC between 9/01/2014 and 4/30/2015. The CDSS, intended to be activated after the diagnosis of acute PE in ED patients age $\geq 18$, calculated the eleven-variable Pulmonary Embolism Severity Index (PESI) score for assistance in the site-of-care disposition decision $[19,20]$. The tool imported 10 of the 11 PESI variables via Web Services application from ED vital sign data and Problem List diagnoses in the EHR. The CDSS was launched by the user with one click from the Epic ED Navigator menu and loaded patient-specific data in less than three seconds. Clinicians were required to assess and record one of eleven PESI variables (altered mental status) and confirm the accuracy of the other data points. After submission, the tool provided a table with PESI stratification data and risk profiles adopted from the literature. Clinicians were also provided with a list of additional reasons to consider admission in patients with low PESI scores (Classes I \& II). The tool was assistive rather than directive, and clinicians were not audited to discern compliance with recommendations. The development and technical details of the tool followed defined principles of effective CDS and practice feedback - such as minimizing cognitive load for end-users [7, 21]. Snapshots of the tool are shown in supplemetary online Appendices 1 and 2.

Our CDSS was deployed at 14 sites across KPNC, and in a pragmatic interventional study design, 10 sites were designated as "active" implementation sites and four were assigned to a "passive" arm. Site designation was on a convenience basis, dependent on the availability of an on-site champion (a staff emergency physician). Ongoing structured promotion included at least three brief educational reviews throughout the study period, monthly enrollment reports comparing each of the intervention sites with each other, iterative physician-specific feedback on every eligible case, and incentivization (a small gift card) for the first three uses of the CDSS. Passive implementation sites received only an introductory educational session and did not receive iterative feedback or gift cards.

Patient-level clinical data - including demographics, PESI variables and score, and ED disposition - were automatically collected from the EHR and transmitted to an internal data center prospectively. Eligibility and missed activations were assessed through weekly retrospective audits drawn from health system electronic data sources and reviewed by a study investigator (DRV). Supplemental patient-level clinical data were extracted from existing health system databases and used discharge diagnosis (ICD-9) codes as in prior work [18, 22, 23]. Electronic data sources are consistent in their definitions across medical centers. Chart validation followed published best practices with the exception that abstractors were not blinded to the larger study hypotheses (which were not based on chart review data) [24].

Inappropriate and missed activations were identified via $100 \%$ audit of enrollments and retrospective review of all ED patients meeting inclusion criteria above.

\subsection{Outcomes}

The primary outcome of this study was appropriate activation of the CDSS. Impact of the tool, in terms of disposition decisions, is being assessed separately. Appropriate activation was defined as completion of the tool in an eligible patient (age 18 or older with a diagnosis of acute PE) in the ED by a treating clinician. Inclusion criteria for retrospective auditing of appropriate activation were: KPNC patients with an ED or inpatient discharge diagnosis (primary or not) of non-gravid PE (ICD-9 codes: 415.11, 415.13, 415.19, 673.20, 673.21, 673.22, 673.24) who underwent a venous thromboembolism imaging study during the ED visit or in the 12 hours preceding ED admission (CPT Codes: 71275, 71260, 71270, 78579, 78580, 78582, 78584, 78585, 78586, 78587, 78588, 78591, $78593,78594,75746,71555,93970,93971)$. Patients were considered ineligible if they had a deep vein thrombosis or PE diagnosis accompanied by radiographic imaging in the prior 30 days. 


\subsection{Methods and Measurements}

In addition to patient level variables, we collected ED provider and facility variables as follows: 1) provider: ED CDSS activating provider age, gender, employment tenure with the medical group, and clinical load at the time of activation opportunity (defined as number of ED patients actively treated by or assigned to the provider at the time that PE imaging results were available), and 2) facility: active versus passive status of facility, ED facility volume at the time imaging results were available (based on comparison to average three-hour block ED census levels), and the presence or absence of an Emergency Severity Index level 1 acuity patient in the department at the time of PE imaging results [25].

At active sites we also collected data on the number of gift cards that the activating physician had received at the time of the activation opportunity ( 0 to a maximum of 3 ).

\subsection{Analysis}

We used bivariate comparisons and multivariable logistic regression with random effects at provider and facility levels to assess the association between appropriate activation of the CDSS and characteristics at the patient, provider and facility levels. For bivariate comparisons, chi-square tests were used and statistical significance was defined as a two-sided $\mathrm{p}$-value $<0.05$.

Our multivariable logistic regression model included variables with p-value $<0.2$ in bivariate comparisons and not expected to be collinear (e.g., age and employment tenure). Incentive receipt history was excluded from the models as it was only applicable to active sites. We used Stata SE 13.1 (StataCorp LP, College Station, TX) for all statistical analyses.

\section{Results}

Study data sources and descriptive CDSS activation results are shown in - Figure 1. Out of 662 eligible patient encounters, the CDSS activation rate was 55\%. At active sites, the tool was activated $68 \%$ of the time (346/512) and at passive sites $13 \%(20 / 150)$.

Comparison of active versus passive facility characteristics is shown in Table 1 . Prior to CDSS deployment, mean PE hospitalization rates were $83.7 \%$ (range 62.2 to $100 \%$ ) at active sites and $87.7 \%$ (range 79.3 to $96.0 \%$ ) at passive sites. Detailed descriptive characteristics of activations versus non-activations are shown in $>$ Table 2.

\subsection{Main results}

Table 3 demonstrates a comparison of descriptive characteristics of active versus passive site enrollments. In bivariate analysis, at active sites we observed an increase in activation rates based on the number of prior gift cards the treating physician had received ( $96 \%$ if 3 prior gift cards versus $60 \%$ if $0, \mathrm{p}<0.0001)$. We also found an association at both active and passive sites between lower than average ED volume at the time of imaging result availability and rates of enrollment (active sites, $\mathrm{p}=0.05$, passive sites, $\mathrm{p}=0.03$ ). At passive sites, we observed that physicians $<$ age 40 had higher rates of activation $(\mathrm{p}=0.03)$.

Our model results are shown in $>$ Table 4. Predictors of higher likelihood of CDSS activation were active site status (odds ratio [OR] 31.1, 95\% CI 11.7, 83.0) and low ED volume at the time of PE diagnosis (OR 1.7, 95\% CI 1.1, 2.7). Predictor of higher likelihood of CDSS activation included patient with PESI scores I or II - compared to III or higher (OR 1.7, 95\% CI: 1.1, 2.5).

\subsection{Limitations}

Our study should be interpreted in the context of certain limitations. First, this was a pragmatic cluster interventional study. While there is a great deal of homogeneity across study settings (e.g., study EDs had similar staffing and system characteristics, shared the same EHR and had mostly similar baseline acute PE diagnosis and hospitalization rates), we cannot exclude facility-level differ- 
ences that confounded our results. However, as shown in $\$$ Table 1 , we did not identify any a priori fundamental differences in active versus passive facilities. Our study utilized a CDSS meant to be activated downstream in the ED process - after the diagnosis of PE was established - and thus uptake rates of our particular tool may not translate to those designed for other temporal stages in the ED throughput process (e.g., prior to imaging). In the same vein, our CDSS did not employ an automatic EHR trigger (e.g., a Best Practice Alert) to drive clinicians to the CDSS as there was not a clean and time-appropriate trigger available for the specific clinical situation. However other ED CDSS studies with upstream targets may likely benefit from such triggers. Similarly, uptake of CDS tools will certainly depend on the nature of the support provided, the ease of manual calculation, and the availability of alternate means of assistance (e.g., MDCalc [MD Aware, LLC, San Francisco, CA]).

Finally, effectively recruiting and maintaining a structured on-site champion requires time and resource allocation to achieve optimum performance. For example, we know that chiefs at passive sites did not recruit and employ clinical champions to promote and audit use of the CDSS, even though there was nothing in our study design that prevented them from doing so. Preliminary analysis of our impact study of the disposition effect of our CDSS suggests that the activation of the tool resulted in increased rates of safe discharge home from the ED for low risk PE (unpublished data). However, we have not yet attempted to evaluate the cost-effectiveness of this approach to KT, though we suspect it performs favorably compared to other approaches such as the use of non-physician quality specialists to retrospectively review compliance with guidelines. It may be that there are particular pieces (e.g., iterative feedback on missed eligible cases) of the active site bundle that are more effective than others and these could be identified and implemented.

\section{Discussion}

In this study we found that performing active on-site tool promotion significantly increased odds of ED providers using a CDSS for site-of-care decision making for acute PE. We also observed that ED volume was inversely associated with likelihood of CDSS activation, supporting the intuitive notion that busier clinicians are more likely to make a gestalt decision rather than seeking out CDS tools. Another confirmation of an intuitive hypothesis in our multivariable analysis was that physicians were more likely to activate the tool when seeing patients with low PESI scores (I or II), than those with scores of III or above. We surmise that in patients with higher scores, clinicians would sometimes conclude that these are "slam-dunk" admissions without the need for decision support tools. Finally, in subgroup analysis, we found that at active sites, CDSS use increased steadily with prior incentive receipt and that at passive sites, younger physicians were more likely to use the tool than older ones.

Peer comparison and iterative feedback and audits have been shown to help drive knowledge translation and performance improvement and are acknowledged as best practices [26-28]. A Cochrane review on the topic reported that this type of feedback works best when it is provided repeatedly, through multiple modalities (e.g., verbally and in person), and by a person who is a supervisor or peer [27]. In this study, our active site study champion met each of these criteria, and we attribute the high uptake of the CDSS at active sites in large part to this on-site dynamic. Of course, this type of feedback loop can be difficult to sustain over time, so it is likely most effective in situations like these, where there is an opportunity to translate validated evidence into practice with the expectation that once translation has occurred there will be an opportunity for sustained practice change.

Conversely, there is peril associated with implementing CDSSs without proper education and feedback. Take for example, the evidence suggesting that adverse drug reaction alerts do little to change clinician-prescribing behavior, such as warnings about opioid prescriptions [29]. Consider as well the potentially deleterious effect of the number of "clicks" that EPs working in an EHR-enabled environment face each shift [30]. Other work suggests that CDSSs are more effective if adapted based on human factor analysis [31]. While there has been significant backlash regarding the benefits of the EHR, we know that certain aspects of it are effective - these include well-designed assistive order sets and condition-specific decision support tools $[18,32]$. We also know that clinicians familiar with using the EHR are receptive to CDSSs through multiple means [33]. The results of this study 
suggest that active KT techniques may help amplify these beneficial attributes and support the contention that the EHR can be used to deliver evidence-based information at the point of care, thus improving workflow, "reducing care variability, and encouraging adherence to best practices" [34].

Our study also suggests that clinicians are less likely to use CDSSs when the departmental clinical volume is greater. This finding has face validity, as we know that there is a greater tendency to cut corners and/or practice via gestalt when busy. Other investigations have associated ED crowding with higher admission rates for transient ischemic attack and stroke [35]. As our CDSS addresses ED disposition decisions, we expect that metrics of ED crowding may also be associated with higher admission rates for patients with acute $\mathrm{PE}$ - low-risk or otherwise.

In the sub-analysis of active sites, we saw, as expected, a strong correlation of CDSS use with prior receipt of an enrollment incentive. This trend continued even once clinicians had reached their predefined maximum of three enrollment incentives, suggesting that an initial incentive, though finite, could be successful in establishing a sustainable behavior pattern. Prior work on the effects of financial incentives on physician performance is mixed [36]; however, our experience is that a small enrollment incentive can reliably and accurately facilitate initial CDSS uptake [23, 37]. Bolstered with a $100 \%$ audit process, we were able to police the incentive system to prevent clinicians from "gaming it" (e.g., enrolling ineligible patients in order to receive an incentive). By making the data collection simple with most variables pre-selected from the EHR, we were able to collect complete data without any missing data points. As such, we see a system of limited physician incentivization as an effective means of observational data collection, one that has a number of advantages over research assistantdriven methods.

Our study also identifies possible demographic barriers to CDSSs; at passive sites, physicians with longer ED practice tenure were less likely to activate the tool than younger physicians. These findings are consistent with previous survey studies demonstrating that younger physicians and those with fewer years since medical school graduation were more likely to be aware of and use specific radiograph-utilization based CDS $[38,39]$. Further study should focus on how to offer decision support to clinicians with different characteristics in a manner that helps them make the best possible use of it. This concept of "personalized" CDSSs is not yet ready for clinical implementation, but the theoretical and technical underpinnings are being laid [40].

\section{Conclusions}

We found that lower facility ED volume status and performing active on-site tool promotion significantly increased odds of CDSS activation. Optimizing CDSS adoption requires active education and iterative feedback from an on-site clinical champion.

\section{Clinical Relevance}

There are numerous barriers that may prevent clinicians from changing their practice in the face of new and validated knowledge. CDSS tools that are supported by active and iterative feedback can help clinicians become more confident in the new best practice and assist to un-diffuse prior practice. Such support may be most important in situations where the clinician is the busiest - times when they are most likely to fall back on heuristics and gestalt - and this presents an opportunity to implement systems that help spin the behavior change wheel.

\section{Conflict of Interest}

The authors declare that they have no conflicts of interest in the research.

\section{Human Subjects Protections}

The KPNC Institutional Review Board reviewed and approved the study protocol under a waiver of informed consent. This study was performed in compliance with the World Medical Association Declaration of Helsinki on Ethical Principles for Medical Research Involving Human Subjects. 


\section{Acknowledgements}

We would like to thank Adina Rauchwerger, MPH, for her administrative support during the study time period and Robert Norris, MD, for sharing his EHR expertise.

\section{Author Contributions}

DWB, DRV, and UKC conceived of study and its design and obtained funding. DWB, DGM, MVK, UKC, AKE, JSL and DRV served as site champions. ASR and RV assisted with data collection, data processing and project management. DWB and DRV oversaw the study as a whole. MER and JH provided statistical advice on study design and JH analyzed the data. DWB and DRV chaired study meetings and DWB and RV drafted the manuscript. All authors contributed substantially to its revision. JH had full access to all of the data in the study and takes responsibility for the integrity of the data and the accuracy of the data analysis. DWB takes responsibility for the manuscript as a whole.

\section{Meeting}

Presented at the Society for Academic Emergency Medicine Annual Meeting, May 2016

\section{Author Disclosures}

None

\section{Acknowledgement}

We are grateful to the The Permanente Federation's Sidney R. Garfield Memorial Fund, Oakland, California and the Garfield Innovation Fund for their generous grants. 


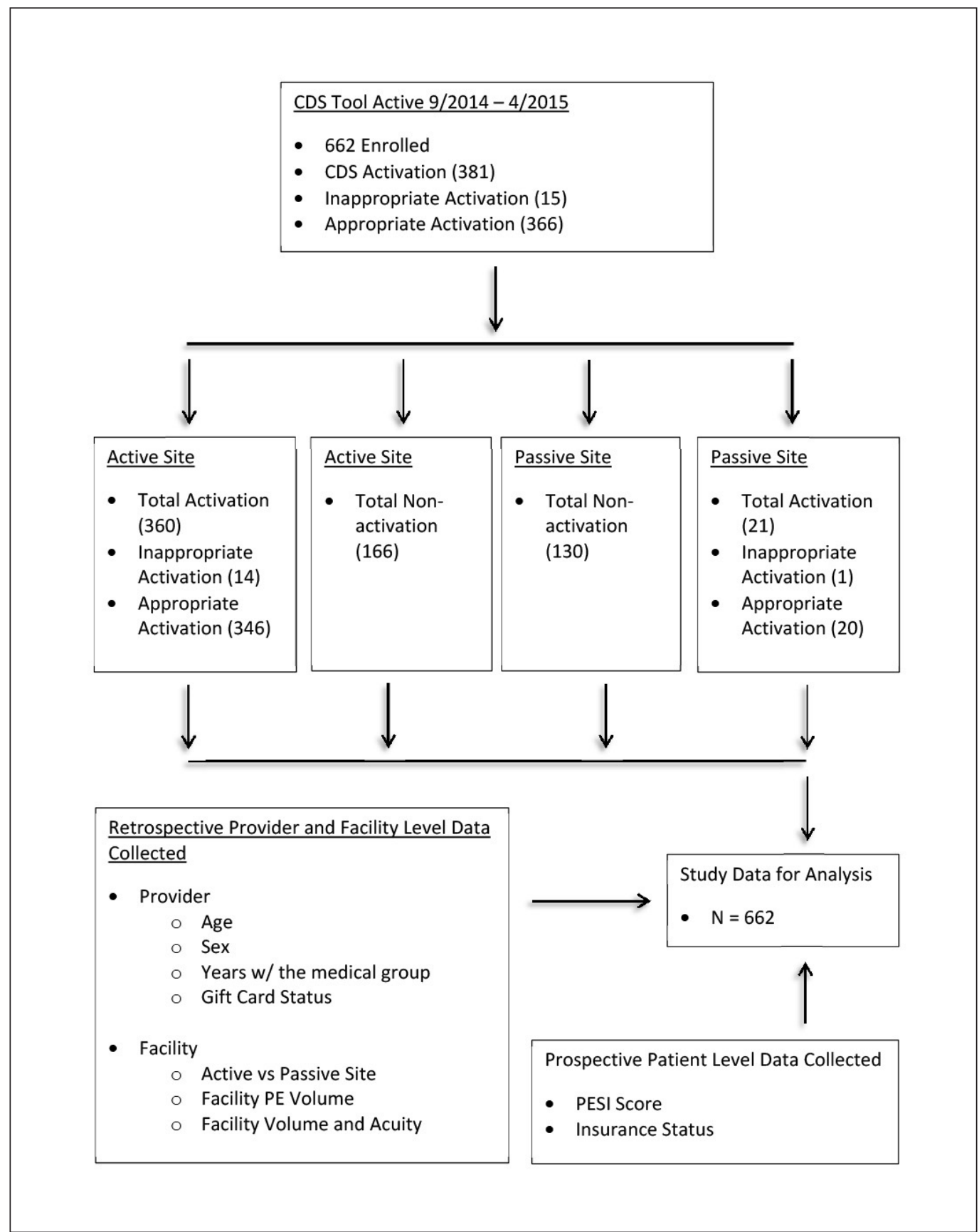

Fig. 1 Study Flow Diagram. Facility PE volume is defined as the relative percent of CDS-eligible cases at treating facility on day of enrollment. Facility Volume refers to the ED patient volume in the facility at the time of imaging result. Facility Acuity refers to the number of ED patients with an Emergency Severity Index of 1 present at the time of imaging result. PESI: Pulmonary Embolism Severity Index, PE: Pulmonary Embolism. 


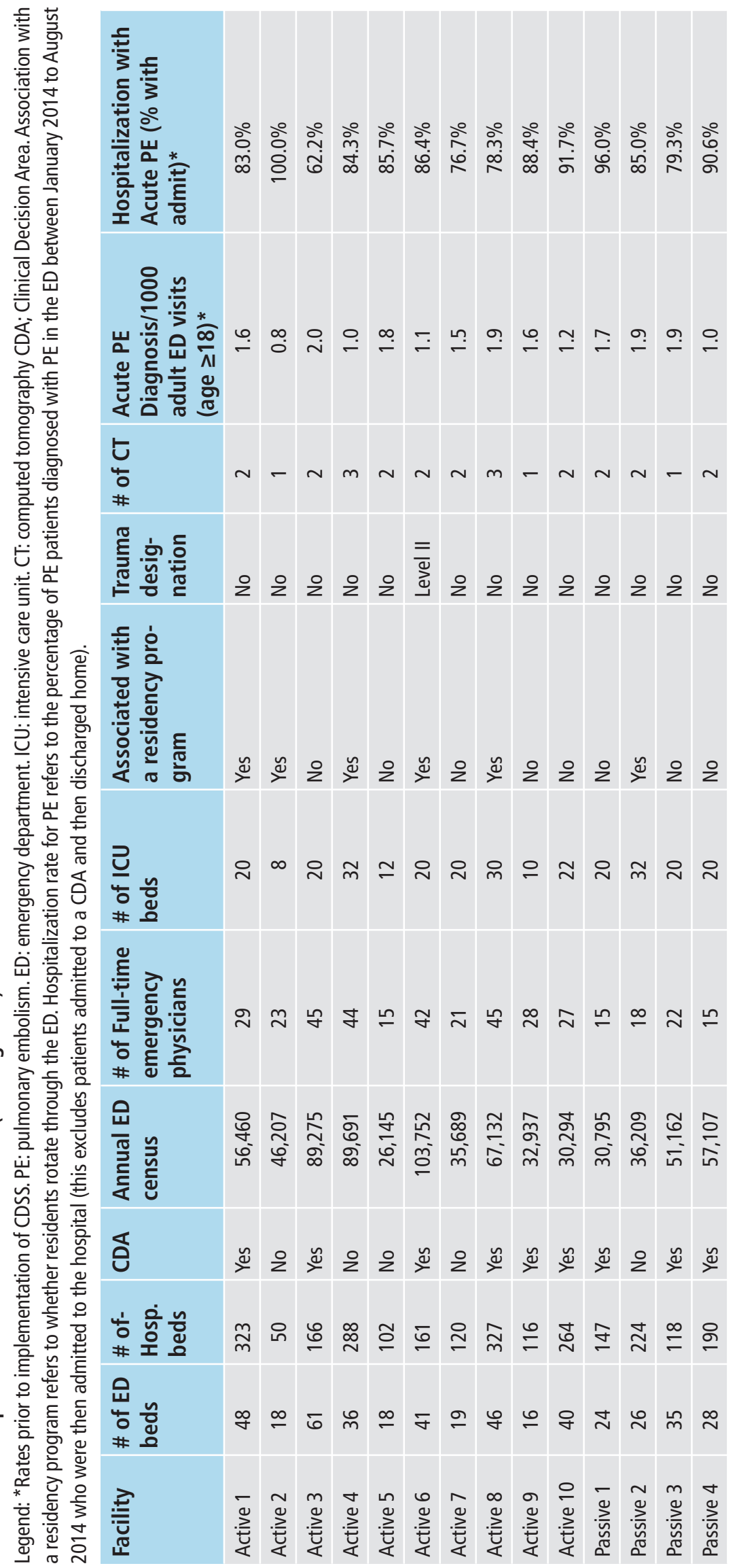


Table 2 Descriptive Characteristics of Study Sample

Legend: Low ED Volume defined as lower or equal to average facility-specific ED census for three-hour time block during which the PE imaging results were obtained. Acuity1 patient is any ED patient with an Emergency Severity Index of 1 present at time of imaging result. KPNC Tenure is physician tenure at time of visit with the medical group. Clinical load is defined by the number of patients currently in the ED and electronically assigned to the enrolling provider. Incentive was a coffee gift card. PESI: Pulmonary Embolism Severity Index , KPNC: Kaiser Permanente Northern California, CDSS: Clinical decision support system, Pt(s): patient(s).

\begin{tabular}{|c|c|c|c|c|c|}
\hline \multicolumn{3}{|c|}{ Characteristics } & \begin{tabular}{|l|} 
Total \\
$662(100.0)$ \\
\end{tabular} & $\begin{array}{l}\text { CDSS Not Acti- } \\
\text { vated } \\
296(100.0)\end{array}$ & $\begin{array}{l}\text { CDSS Acti- } \\
\text { vated } \\
366(100.0)\end{array}$ \\
\hline \multirow{7}{*}{ Facility } & \multirow{3}{*}{ Site } & & & & \\
\hline & & rassive & $130(22.1)$ & $130(43.9)$ & $20(3.3)$ \\
\hline & & Active & $512(77.3)$ & $166(56.1)$ & $346(94.5)$ \\
\hline & \multirow[t]{2}{*}{ Low ED Volume } & No & $334(50.5)$ & $166(56.1)$ & $168(45.9)$ \\
\hline & & Yes & $328(49.6)$ & $130(43.9)$ & $198(54.1)$ \\
\hline & \multirow[t]{2}{*}{ Presence Acuity1 Pt. } & No & $538(81.3)$ & $259(87.5)$ & $279(76.2)$ \\
\hline & & Yes & $124(18.7)$ & $37(12.5)$ & $87(23.8)$ \\
\hline \multirow[t]{6}{*}{ Patient } & \multirow[t]{4}{*}{ Insurance } & Commercial & $268(40.5)$ & $114(38.5)$ & $154(42.1)$ \\
\hline & & Medicaid & $29(4.4)$ & $11(3.7)$ & $18(4.9)$ \\
\hline & & Medicare & $316(47.7)$ & $151(51.0)$ & $165(45.1)$ \\
\hline & & Unknown & $49(7.4)$ & $20(6.8)$ & $29(7.9)$ \\
\hline & \multirow[t]{2}{*}{ PESI class } & I, II & $273(41.2)$ & $107(36.2)$ & $166(45.4)$ \\
\hline & & III, IV, V & $389(58.8)$ & $189(63.9)$ & $200(54.6)$ \\
\hline \multirow[t]{13}{*}{ Provider } & \multirow[t]{2}{*}{ Gender } & Female & $252(38.1)$ & $104(35.1)$ & $148(40.4)$ \\
\hline & & Male & $410(61.9)$ & $192(64.9)$ & $218(59.6)$ \\
\hline & \multirow[t]{2}{*}{ Age } & $<40$ & $288(43.5)$ & $107(36.2)$ & $181(49.5)$ \\
\hline & & $40+$ & $374(56.5)$ & $189(63.9)$ & $185(50.6)$ \\
\hline & \multirow[t]{2}{*}{ KPNC Tenure } & $<5$ yrs & $451(68.1)$ & $189(63.9)$ & $262(71.6)$ \\
\hline & & $5+y r s$ & $211(31.9)$ & $107(36.2)$ & $104(28.4)$ \\
\hline & \multirow[t]{2}{*}{ Clinical Load (Pts) } & $<5$ & $362(54.7)$ & $151(51.0)$ & $211(57.7)$ \\
\hline & & $5+$ & $300(45.3)$ & $145(49.0)$ & $155(42.4)$ \\
\hline & \multirow[t]{5}{*}{ Incentives Received } & 0 & $325(49.1)$ & $131(44.3)$ & $194(53.0)$ \\
\hline & & 1 & $116(17.5)$ & $26(8.8)$ & $90(24.6)$ \\
\hline & & 2 & $48(7.3)$ & $8(2.7)$ & $40(10.9)$ \\
\hline & & 3 & $23(3.5)$ & $1(0.3)$ & $22(6.0)$ \\
\hline & & N/A & $150(22.7)$ & $130(43.9)$ & $20(5.5)$ \\
\hline
\end{tabular}


Table 3 Descriptive Characteristics of Active \& Passive Sites

Legend: Low ED Volume defined as lower or equal to average facility-specific ED census for three-hour time block during which the PE imaging results were obtained. Acuity1 patient is any ED patient with an Emergency Severity Index of 1 present at time of imaging result. KPNC Tenure is physician employment tenure with KPNC at time of visit. Clinical load is defined by the number of patients currently in the ED and electronically assigned to the enrolling provider. Incentive was a coffee gift card. PESI: Pulmonary Embolism Severity Index, KPNC: Kaiser Permanente Northern California, CDSS: Clinical decision support system, Pt(s): patient(s).

\begin{tabular}{|c|c|c|c|c|c|c|c|c|}
\hline \multirow{2}{*}{\multicolumn{3}{|c|}{ Characteristics }} & \multicolumn{3}{|c|}{ Active Sites } & \multicolumn{3}{|c|}{ Passive Sites } \\
\hline & & & \multirow{2}{*}{$\begin{array}{l}\text { Total } \\
512\end{array}$} & \multirow{2}{*}{$\begin{array}{l}\text { CDSS - } \\
\text { no } \\
166\end{array}$} & \multirow{2}{*}{$\begin{array}{l}\text { CDSS - } \\
\text { yes } \\
346\end{array}$} & \multirow{2}{*}{$\begin{array}{l}\text { Total } \\
150\end{array}$} & \multirow{2}{*}{$\begin{array}{l}\text { CDSS - } \\
\text { no } \\
130\end{array}$} & \multirow{2}{*}{$\begin{array}{l}\text { CDSS - } \\
\text { yes } \\
20\end{array}$} \\
\hline & & $\mathbf{N}$ & & & & & & \\
\hline \multirow[t]{4}{*}{ Facility } & \multirow{2}{*}{$\begin{array}{l}\text { Low ED Vol- } \\
\text { ume }\end{array}$} & No & $49.8 \%$ & $56.0 \%$ & $46.8 \%$ & $52.7 \%$ & $56.2 \%$ & $30.0 \%$ \\
\hline & & Yes & $50.2 \%$ & $44.0 \%$ & $53.2 \%$ & $47.3 \%$ & $43.9 \%$ & $70.0 \%$ \\
\hline & \multirow{2}{*}{$\begin{array}{l}\text { Presence } \\
\text { Acuity1 }\end{array}$} & No & $76.8 \%$ & $80.1 \%$ & $75.1 \%$ & $96.7 \%$ & $96.9 \%$ & $95.0 \%$ \\
\hline & & Yes & $23.2 \%$ & $19.9 \%$ & $24.9 \%$ & $3.3 \%$ & $3.1 \%$ & $5.0 \%$ \\
\hline \multirow[t]{6}{*}{ Patient } & \multirow[t]{4}{*}{ Insurance } & Commercial & $40.4 \%$ & $37.4 \%$ & $41.9 \%$ & $40.7 \%$ & $40.0 \%$ & $45.0 \%$ \\
\hline & & Medicaid & $4.9 \%$ & $4.2 \%$ & $5.2 \%$ & $2.7 \%$ & $3.1 \%$ & $0.0 \%$ \\
\hline & & Medicare & $46.7 \%$ & $51.2 \%$ & $44.5 \%$ & $51.3 \%$ & $50.8 \%$ & $55.0 \%$ \\
\hline & & Unknown & $8.0 \%$ & $7.2 \%$ & $8.4 \%$ & $5.3 \%$ & $6.2 \%$ & $0.0 \%$ \\
\hline & \multirow[t]{2}{*}{ PESI Class } & I, II & $43.8 \%$ & $40.4 \%$ & $45.4 \%$ & $32.7 \%$ & $30.8 \%$ & $45.0 \%$ \\
\hline & & III, IV, V & $56.3 \%$ & $59.6 \%$ & $54.6 \%$ & $67.3 \%$ & $69.2 \%$ & $55.0 \%$ \\
\hline \multirow[t]{12}{*}{ Provider } & \multirow[t]{2}{*}{ Gender } & Female & $39.1 \%$ & $37.4 \%$ & $39.9 \%$ & $34.7 \%$ & $32.3 \%$ & $50.0 \%$ \\
\hline & & Male & $60.9 \%$ & $62.7 \%$ & $60.1 \%$ & $65.3 \%$ & $67.7 \%$ & $50.0 \%$ \\
\hline & \multirow[t]{2}{*}{ Age } & $<40$ & $47.7 \%$ & $44.0 \%$ & $49.4 \%$ & $29.3 \%$ & $26.2 \%$ & $50.0 \%$ \\
\hline & & $40+$ & $52.3 \%$ & $56.0 \%$ & $50.6 \%$ & $70.7 \%$ & $73.9 \%$ & $50.0 \%$ \\
\hline & \multirow[t]{2}{*}{ KPNC Tenure } & $<5$ yrs & $71.5 \%$ & $71.7 \%$ & $71.4 \%$ & $56.7 \%$ & $53.9 \%$ & $75.0 \%$ \\
\hline & & $5+y r s$ & $28.5 \%$ & $28.3 \%$ & $28.6 \%$ & $43.3 \%$ & $46.2 \%$ & $25.0 \%$ \\
\hline & \multirow{2}{*}{$\begin{array}{l}\text { Clinical Load } \\
\text { (Pts) }\end{array}$} & $<5$ & $56.6 \%$ & $54.2 \%$ & $57.8 \%$ & $48.0 \%$ & $46.9 \%$ & $55.0 \%$ \\
\hline & & $5+$ & $43.4 \%$ & $45.8 \%$ & $42.2 \%$ & $52.0 \%$ & $53.1 \%$ & $45.0 \%$ \\
\hline & \multirow{4}{*}{$\begin{array}{l}\text { Incentives } \\
\text { Received }\end{array}$} & 0 & $63.5 \%$ & $78.9 \%$ & $56.1 \%$ & $\mathrm{~N} / \mathrm{A}$ & $\mathrm{N} / \mathrm{A}$ & N/A \\
\hline & & 1 & $22.7 \%$ & $15.7 \%$ & $26.0 \%$ & $\mathrm{~N} / \mathrm{A}$ & $\mathrm{N} / \mathrm{A}$ & N/A \\
\hline & & 2 & $9.4 \%$ & $4.8 \%$ & $11.6 \%$ & $\mathrm{~N} / \mathrm{A}$ & $\mathrm{N} / \mathrm{A}$ & $N / A$ \\
\hline & & 3 & $4.5 \%$ & $0.6 \%$ & $6.4 \%$ & N/A & N/A & $\mathrm{N} / \mathrm{A}$ \\
\hline
\end{tabular}


Table 4 Multivariable analysis results: characteristics associated with CDSS activation

Legend: Model: logistic regression, with random effect at provider and facility levels. Low ED Volume defined as lower or equal to average facility-specific ED census for three-hour time block during which the PE imaging results were obtained. Acuity1 Patient is any ED patient with an Emergency Severity Index of 1 present at time of imaging result. Clinical load is defined by the number of patients currently in the ED and electronically assigned to the enrolling provider. PESI: Pulmonary Embolism Severity Index, OR: Odds Ratio, ED: Emergency Department

\begin{tabular}{|c|c|c|c|c|c|c|}
\hline \multirow[b]{2}{*}{ Facility } & \multirow{2}{*}{$\begin{array}{l}\text { Characteristics } \\
\text { Site }\end{array}$} & \multirow[b]{2}{*}{ Active } & \multirow{2}{*}{$\begin{array}{l}\text { Reference } \\
\text { Passive }\end{array}$} & \multirow{2}{*}{$\begin{array}{l}\text { OR } \\
31.1\end{array}$} & \multicolumn{2}{|c|}{$95 \% \mathrm{Cl}$} \\
\hline & & & & & 11.7 & 83.0 \\
\hline & Low ED Volume & Yes & No & 1.7 & 1.1 & 2.7 \\
\hline & Acuity 1 Patient & Yes & No & 1.2 & 0.7 & 2.3 \\
\hline \multirow[t]{3}{*}{ Provider } & Sex & Female & Male & 0.9 & 0.5 & 1.6 \\
\hline & Age & $40+$ & $<40$ & 0.6 & 0.4 & 1.1 \\
\hline & Clinical Load (Pts) & $5+$ & $<5$ & 0.9 & 0.6 & 1.4 \\
\hline Patient & PESI Class & I, II & III+ & 1.7 & 1.1 & 2.5 \\
\hline
\end{tabular}




\section{References}

1. McGlynn EA, Asch SM, Adams J, Keesey J, Hicks J, DeCristofaro A, Kerr EA. The quality of health care delivered to adults in the United States. The New England journal of medicine 2003; 348(26): 2635-2645. doi: 10.1056/NEJMsa022615. PubMed PMID: 12826639.

2. Grimshaw JM, Eccles MP, Lavis JN, Hill SJ, Squires JE. Knowledge translation of research findings. Implementation science: IS 2012; 7: 50. doi: 10.1186/1748-5908-7-50. PubMed PMID: 22651257; PubMed Central PMCID: PMC3462671.

3. Balas EA, Boren SA. Managing clinical knowledge for health care improvement. Yearbook of Medical Informatics 2000; 65(70).

4. Davidoff F. On the undiffusion of established practices. JAMA internal medicine 2015; 175(5): 809-811. doi: 10.1001/jamainternmed.2015.0167. PubMed PMID: 25774743.

5. Michie S, van Stralen MM, West R. The behaviour change wheel: a new method for characterising and designing behaviour change interventions. Implementation science: IS 2011; 6: 42. doi: 10.1186/1748-5908-6-42. PubMed PMID: 21513547; PubMed Central PMCID: PMC3096582.

6. Diner BM, Carpenter CR, O'Connell T, Pang P, Brown MD, Seupaul RA, Celentano JJ, Mayer D, Members K-CTI. Graduate medical education and knowledge translation: role models, information pipelines, and practice change thresholds. Academic emergency medicine : official journal of the Society for Academic Emergency Medicine 2007; 14(11): 1008-1014. doi: 10.1197/j.aem.2007.07.003. PubMed PMID: 17967963.

7. Carpenter CR, Milne WK. Knowledge translation and implementation science. Pseudoscience or the missing link between research and the bedside. Emergency Medicine \& Acute Care Essays 2015; 39 (6) $1-4$.

8. Lang ES, Wyer PC, Eskin B. Executive summary: Knowledge translation in emergency medicine: establishing a research agenda and guide map for evidence uptake. Academic emergency medicine : official journal of the Society for Academic Emergency Medicine 2007; 14(11): 915-918. doi: 10.1197/j.aem.2007.07.005. PubMed PMID: 17923716.

9. Kawamoto K, Houlihan CA, Balas EA, Lobach DF. Improving clinical practice using clinical decision support systems: a systematic review of trials to identify features critical to success. Bmj 2005; 330(7494): 765. doi: 10.1136/bmj.38398.500764.8F. PubMed PMID: 15767266; PubMed Central PMCID: PMC555881.

10. Melnick ER, Nielson JA, Finnell JT, Bullard MJ, Cantrill SV, Cochrane DG, Halamka JD, Handler JA, Holroyd BR, Kamens D, Kho A, McClay J, Shapiro JS, Teich J, Wears RL, Patel SJ, Ward MF, Richardson LD. Delphi consensus on the feasibility of translating the ACEP clinical policies into computerized clinical decision support. Annals of emergency medicine 2010; 56(4): 317-320. doi: 10.1016/j.annemergmed.2010.03.006. PubMed PMID: 20363531.

11. Bright TJ, Wong A, Dhurjati R, Bristow E, Bastian L, Coeytaux RR, Samsa G, Hasselblad V, Williams JW, Musty MD, Wing L, Kendrick AS, Sanders GD, Lobach D. Effect of Clinical Decision-Support Systems: A Systematic Review. Ann Intern Med 2012: 157(1): 29-43. Epub 2012/04/25. doi: 0003-4819-157-1-201207030-00450 [pii] 10.1059/0003-4819-157-1-201207030-00450. PubMed PMID: 22529043.

12. Roy PM, Durieux P, Gillaizeau F, Legall C, Armand-Perroux A, Martino L, Hachelaf M, Dubart AE, Schmidt J, Cristiano M, Chretien JM, Perrier A, Meyer G. A computerized handheld decision-support system to improve pulmonary embolism diagnosis: a randomized trial. Ann Intern Med 2009; 151(10): 677-686. Epub 2009/11/19. doi: 151/10/677 [pii] 10.1059/0003-4819-151-10-200911170-00003. PubMed PMID: 19920268.

13. Drescher FS, Chandrika S, Weir ID, Weintraub JT, Berman L, Lee R, Van Buskirk PD, Wang Y, Adewunmi A, Fine JM. Effectiveness and acceptability of a computerized decision support system using modified Wells criteria for evaluation of suspected pulmonary embolism. Ann Emerg Med 2011; 57(6): 613-621. Epub 2010/11/06. doi: S0196-0644(10)01557-X [pii] 10.1016/j.annemergmed.2010.09.018. PubMed PMID: 21050624.

14.Patel PB, Vinson DR. Team assignment system: expediting emergency department care. Annals of emergency medicine 2005; 46(6): 499-506. Epub 2005/11/26. doi: 10.1016/j.annemergmed.2005.06.012. PubMed PMID: 16308063.

15. Escobar GJ, Greene JD, Scheirer P, Gardner MN, Draper D, Kipnis P. Risk-adjusting hospital inpatient mortality using automated inpatient, outpatient, and laboratory databases. Medical care 2008; 46(3): 232-239. doi: 10.1097/MLR.0b013e3181589bb6. PubMed PMID: 18388836.

16. Escobar GJ, Ragins A, Scheirer P, Liu V, Robles J, Kipnis P. Nonelective Rehospitalizations and Postdischarge Mortality: Predictive Models Suitable for Use in Real Time. Medical care 2015; 53(11): 916-923. doi: 10.1097/MLR.0000000000000435. PubMed PMID: 26465120. 
17.van Walraven C, Escobar GJ, Greene JD, Forster AJ. The Kaiser Permanente inpatient risk adjustment methodology was valid in an external patient population. Journal of clinical epidemiology 2010; 63(7): 798-803. doi: 10.1016/j.jclinepi.2009.08.020. PubMed PMID: 20004550.

18. Ballard DW, Kim AS, Huang J, Park DK, Kene MV, Chettipally UK, Iskin HR, Hsu J, Vinson DR, Mark DG, Reed ME, Investigators KCN. Implementation of Computerized Physician Order Entry Is Associated With Increased Thrombolytic Administration for Emergency Department Patients With Acute Ischemic Stroke. Annals of emergency medicine 2015; 66(6): 601-10. doi: 10.1016/j.annemergmed.2015.07.018. PubMed PMID: 26362574.

19. Aujesky D, Obrosky DS, Stone RA, Auble TE, Perrier A, Cornuz J, Roy PM, Fine MJ. Derivation and validation of a prognostic model for pulmonary embolism. American journal of respiratory and critical care medicine 2005; 172(8): 1041-1046. doi: 10.1164/rccm.200506-862OC. PubMed PMID: 16020800; PubMed Central PMCID: PMC2718410.

20. Aujesky D, Roy PM, Le Manach CP, Verschuren F, Meyer G, Obrosky DS, Stone RA, Cornuz J, Fine MJ. Validation of a model to predict adverse outcomes in patients with pulmonary embolism. European heart journal 2006; 27(4): 476-481. doi: 10.1093/eurheartj/ehi588. PubMed PMID: 16207738.

21.Brehaut JC, Hamm R, Majumdar S, Papa F, Lott A, Lang E. Cognitive and social issues in emergency medicine knowledge translation: a research agenda. Academic emergency medicine: official journal of the Society for Academic Emergency Medicine 2007; 14(11): 984-990. doi: 10.1197/j.aem.2007.06.025. PubMed PMID: 17893396.

22. Reed M, Huang J, Brand R, Graetz I, Neugebauer R, Fireman B, Jaffe M, Ballard DW, Hsu J. Implementation of an outpatient electronic health record and emergency department visits, hospitalizations, and office visits among patients with diabetes. Jama 2013; 310(10): 1060-1065. doi: 10.1001/jama.2013.276733. PubMed PMID: 24026601.

23. Ballard DW, Reed ME, Singh N, Rauchwerger AS, Hamity CA, Warton EM, Chettipally UK, Mark DG, Vinson DR, Investigators KPCN. Emergency Department Management of Atrial Fibrillation and Flutter and Patient Quality of Life at One Month Postvisit. Ann Emerg Med 2015; 66(6): 646-654 e2. doi: 10.1016/j.annemergmed.2015.04.011. PubMed PMID: 26033532.

24.Kaji AH, Schriger D, Green S. Looking through the retrospectoscope: reducing bias in emergency medicine chart review studies. Ann Emerg Med 2014; 64(3): 292-298. doi: 10.1016/j.annemergmed.2014.03.025. PubMed PMID: 24746846.

25. Song H, Tucker AL, Murrell KL. The Diseconomies of Queue Pooling: An Empirical Investigation of Emergency Department Length of Stay. Management Science 2015; 61(12): 3032-3053. doi: http://dx.doi.org/10.1287/mnsc.2014.2118.

26. Rogers Rle G, Narvaez Y, Venkatesh AK, Fleischman W, Hall MK, Taylor RA, Hersey D, Sette L, Melnick ER. Improving emergency physician performance using audit and feedback: a systematic review. The American journal of emergency medicine 2015; 33(10): 1505-1514. doi: 10.1016/j.ajem.2015.07.039. PubMed PMID: 26296903.

27. Ivers N, Jamtvedt G, Flottorp S, Young JM, Odgaard-Jensen J, French SD, O‘Brien MA, Johansen M, Grimshaw J, Oxman AD. Audit and feedback: effects on professional practice and healthcare outcomes. The Cochrane database of systematic reviews. 2012; 6: CD000259. doi: 10.1002/14651858.CD000259.pub3. PubMed PMID: 22696318.

28. Meeker D, Linder JA, Fox CR, Friedberg MW, Persell SD, Goldstein NJ, Knight TK, Hay JW, Doctor JN. Effect of Behavioral Interventions on Inappropriate Antibiotic Prescribing Among Primary Care Practices: A Randomized Clinical Trial. Jama 2016; 315(6): 562-570. doi: 10.1001/jama.2016.0275. PubMed PMID: 26864410.

29. Genco EK, Forster JE, Flaten H, Goss F, Heard KJ, Hoppe J, Monte AA. Clinically Inconsequential Alerts: The Characteristics of Opioid Drug Alerts and Their Utility in Preventing Adverse Drug Events in the Emergency Department. Annals of emergency medicine 2015. doi: 10.1016/j.annemergmed.2015.09.020. PubMed PMID: 26553282.

30.Hill RG, Jr., Sears LM, Melanson SW. 4000 clicks: a productivity analysis of electronic medical records in a community hospital ED. The American journal of emergency medicine 2013; 31(11): 1591-1594. doi: 10.1016/j.ajem.2013.06.028. PubMed PMID: 24060331.

31. Yadav K, Chamberlain JM, Lewis VR, Abts N, Chawla S, Hernandez A, Johnson J, Tuveson G, Burd RS. Designing Real-time Decision Support for Trauma Resuscitations. Academic emergency medicine : official journal of the Society for Academic Emergency Medicine 2015; 22(9): 1076-1084. doi: 10.1111/acem.12747. PubMed PMID: 26300010.

32. Ballesca MA, Laguardia JC, Lee PC, Hwang AM, Park DK, Gardner MN, Turk BJ, Kipnis P, Escobar GJ. An electronic order set for acute myocardial infarction is associated with improved patient outcomes through 
better adherence to clinical practice guidelines. J Hosp Med 2014; 9(3): 155-161. doi: 10.1002/jhm.2149. PubMed PMID: 24493376.

33. Sheehan B, Nigrovic LE, Dayan PS, Kuppermann N, Ballard DW, Alessandrini E, Bajaj L, Goldberg H, Hoffman J, Offerman SR, Mark DG, Swietlik M, Tham E, Tzimenatos L, Vinson DR, Jones GS, Bakken S, Pediatric Emergency Care Applied Research N. Informing the design of clinical decision support services for evaluation of children with minor blunt head trauma in the emergency department: a sociotechnical analysis. Journal of biomedical informatics 2013; 46(5): 905-913. doi: 10.1016/j.jbi.2013.07.005. PubMed PMID: 23892207.

34. Hwang U, McCarthy ML, Aronsky D, Asplin B, Crane PW, Craven CK, Epstein SK, Fee C, Handel DA, Pines JM, Rathlev NK, Schafermeyer RW, Zwemer FL, Jr., Bernstein SL. Measures of crowding in the emergency department: a systematic review. Academic emergency medicine: official journal of the Society for Academic Emergency Medicine 2011; 18(5): 527-538. doi: 10.1111/j.1553-2712.2011.01054.x. PubMed PMID: 21569171.

35. Ben-Yakov M, Kapral MK, Fang J, Li S, Vermeulen MJ, Schull MJ. The Association Between Emergency Department Crowding and the Disposition of Patients With Transient Ischemic Attack or Minor Stroke. Academic emergency medicine : official journal of the Society for Academic Emergency Medicine. 2015. doi: 10.1111/acem.12766. PubMed PMID: 26398233.

36. Hollander MJ, Kadlec H. Incentive-Based Primary Care: Cost and Utilization Analysis. The Permanente journal 2015; 19(4): 46-56. doi: 10.7812/TPP/15-045. PubMed PMID: 26263389.

37. Nishijima DK, Offerman SR, Ballard DW, Vinson DR, Chettipally UK, Rauchwerger AS, Reed ME, Holmes JF, Clinical Research in Emergency S, Treatment N. Immediate and delayed traumatic intracranial hemorrhage in patients with head trauma and preinjury warfarin or clopidogrel use. Annals of emergency medicine 2012; 59(6): 460-468 e1-7. doi: 10.1016/j.annemergmed.2012.04.007. PubMed PMID: 22626015; PubMed Central PMCID: PMC3361700.

38. Eagles D, Stiell IG, Clement CM, Brehaut J, Taljaard M, Kelly AM, Mason S, Kellermann A, Perry JJ. International survey of emergency physicians' awareness and use of the Canadian Cervical-Spine Rule and the Canadian Computed Tomography Head Rule. Academic emergency medicine : official journal of the Society for Academic Emergency Medicine 2008; 15(12): 1256-1261. doi: 10.1111/j.1553-2712.2008.00265.x. PubMed PMID: 18945241.

39. Graham ID, Stiell IG, Laupacis A, O'Connor AM, Wells GA. Emergency physicians` attitudes toward and use of clinical decision rules for radiography. Academic emergency medicine : official journal of the Society for Academic Emergency Medicine 1998; 5(2): 134-140. PubMed PMID: 9492134.

40. Kastner M, Estey E, Perrier L, Graham ID, Grimshaw J, Straus SE, Zwarenstein M, Bhattacharyya O. Understanding the relationship between the perceived characteristics of clinical practice guidelines and their uptake: protocol for a realist review. Implementation science: IS 2011; 6: 69. doi: 10.1186/1748-5908-6-69. PubMed PMID: 21733160; PubMed Central PMCID: PMC3224565. 